\title{
Digital Rectal Examination (DRE); A Despised Clinical Sign among Medical Students?
}

\section{Dr. Nwachukwu AC}

\begin{abstract}
Background: Digital Rectal Examination is used in the diagnosis of different urogenital and lower gastrointestinal pathology.

The knowledge and practice of this is taught in the medical schools.

Final year medical students who have completed their clinical rotations are expected to have learnt and practiced this in the course of their training.

This study evaluates the knowledge and practice of DRE amongst final year medical students of University of Ibadan.

Methodology:- A cross sectional study of 2 consecutive sets of final year medical students of University of Ibadan, was conducted just before their final examination using a semi-structure questionnaire. This was done at completion of all their clinical rotation.
\end{abstract}

Result:- Out of the 120 medical students who consented to the study, $110(92 \%)$ have been taught DRE. Eighty seven (79\%) of those who have been taught, have done digital rectal examination.

Sixty-six $(60 \%)$ have done 3 or less throughout their ward postings.

Ten precent of the students did not perform DRE due to patient's refusal while $15 \%$ did not want to disturb the patient.

Nineteen percent do not believe DRE is for medical student, while $20 \%$ believe that their choice of future specialty affected their attitude toward DRE.

Fifty students representing $41.7 \%$ of all students who took part in the study think DRE is not necessary for patients with hemoptysis.

$58.5 \%$ of all the students regretted not applying themselves fully to their postings.

Conclusion:- While most student have been taught Digital Rectal Examination (DRE), the practice of this important physical sign falls short of expectation.

There is need for trainers to emphasize the importance of mastering clinical signs by repeated performance in order to make these young medical students better clinicians in future.

Index Terms - Digital Rectal Examination, Knowledge, Practice, Medical Students.

\section{INTRODUCTION}

Digital rectal examination has been proven to be an important clinical examination and test in the diagnosis of prostate cancer. It is also very useful in the detection of rectal tumors among other uses. Our medical students are our future clinicians and the custodians our health in no distant time. Teaching of this important examination go on in our medical schools, however, what is not known is how well they are

Dr. Nwachukwu AC, Department of Surgery, Chukwuemeka Odumegwu Ojukwu University/Teaching Hospital, (COOU)/COOUTH Awka, Nigeria imbibing this in their day to day practical. While there are a few literatures in Nigeria which have looked into this, reassuring ourselves of the improvement of knowledge and practice of this test is very pertinent, otherwise there has to be a concerted effort by all clinicians in re-emphasizing the importance of this clinical sign.

Many researchers have shown the importance of digital rectal examination in the diagnosis of prostate cancer. Its use as a single tool or in combination with other tests has been demonstrated in several studies as very relevant in the evaluation and diagnosis of prostate diseases. The abandonment of DRE was short-lived as it was noted that it could detect cancers in people with PSA greater than 4.0ug/l. Its sensitivity increases as the value of PSA gets higher[2].

It was found that the use of DRE and PSA in cancer screening enhanced cancer detection. The cancer detection rate was $3.2 \%$ for digital rectal examination, $4.6 \%$ for PSA and $5.8 \%$ for the 2 methods combined. [3].

Digital rectal examination has a high positive predictive value in detection of prostate cancer, and cancers detected this way has clinical features of potentially curable cancer[4].

Even though some researchers found out that PSA is a superior test to transrectal ultrasonography and DRE, they agreed that DRE in combination with any of the two tests give a superior detection outcome than PSA alone.[5]

Over the years, some urologists have excluded DRE from the routine screening tests for prostate cancer[6] but however, reports have shown that DRE has a high specificity and a high negative predictive value in the diagnosis of prostate disease[7] .

So many studies have also confirmed the importance and use of DRE in the diagnosis of prostate cancer . Some show its diagnostic value[8],others show its high specificity and negative predictive value, while another shows its $75 \%$ sensitivity in the diagnosis of prostate cancer[9].

All these studies are pointers to the fact that digital rectal examination is a very important clinical sign which I am therefore investigating to find out how our medical students are learning and practicing it.

\section{Methodology}

A cross sectional study of 2 consecutive sets of final year medical students of University of Ibadan, sets, was conducted after the completion of all their clinical postings up to the commencement of their final examination using a semi-structure questionnaire. 150 students returned their questionnaires. Out of this number, 120 of them were found to have completed their questionnaires properly.

The results were analysed using excel spread sheet and 
presented with appropriate charts.

\section{RESULTS}

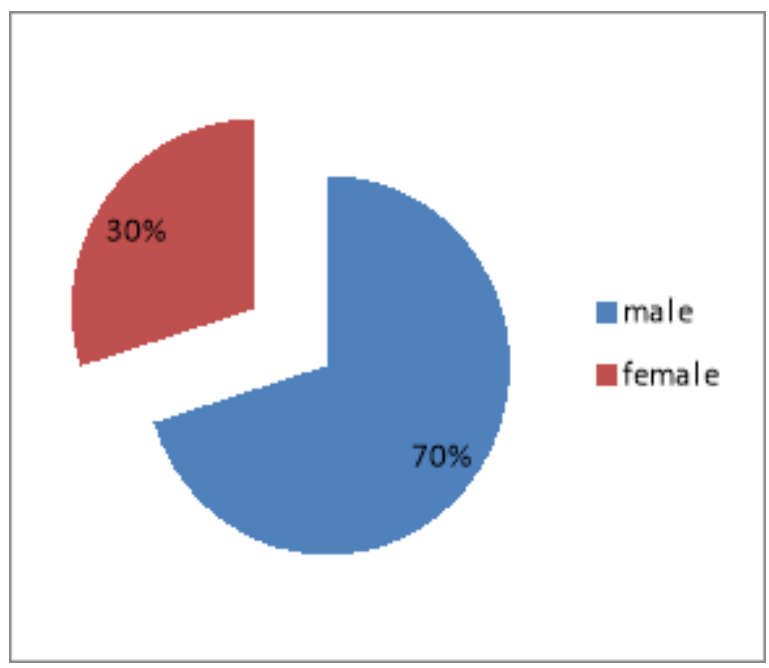

Fig. 1: sex of resondents

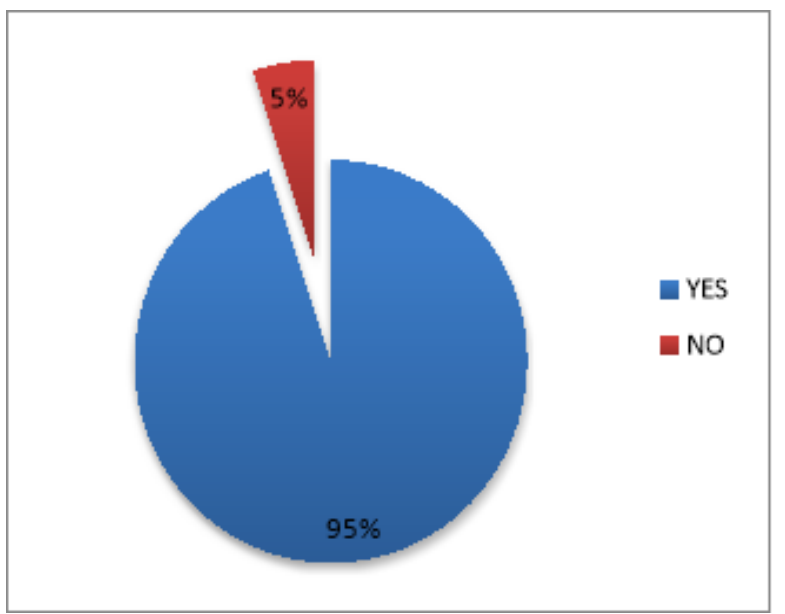

Fig. 2: have you been taught digital rectal examination (dre)

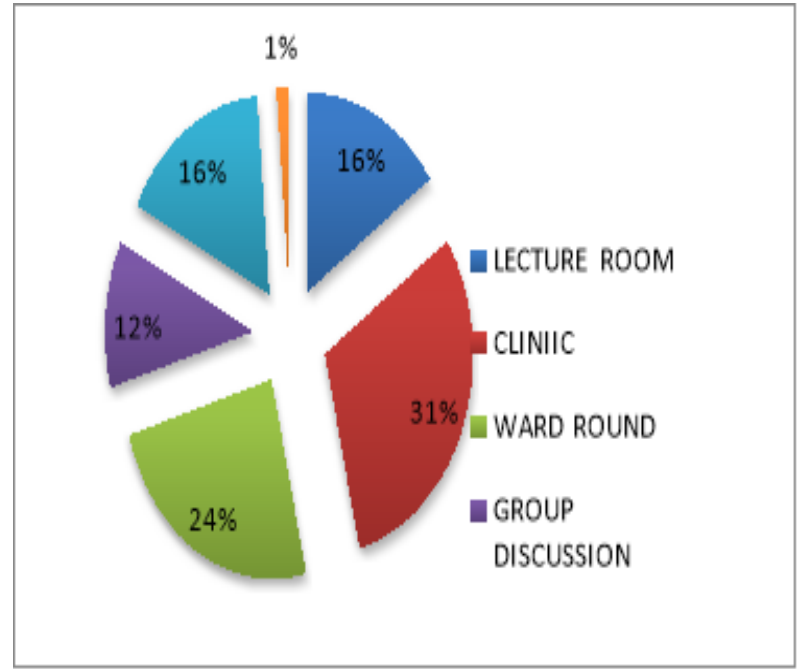

Fig. 3: if yes to fig 2, where you taught dre?

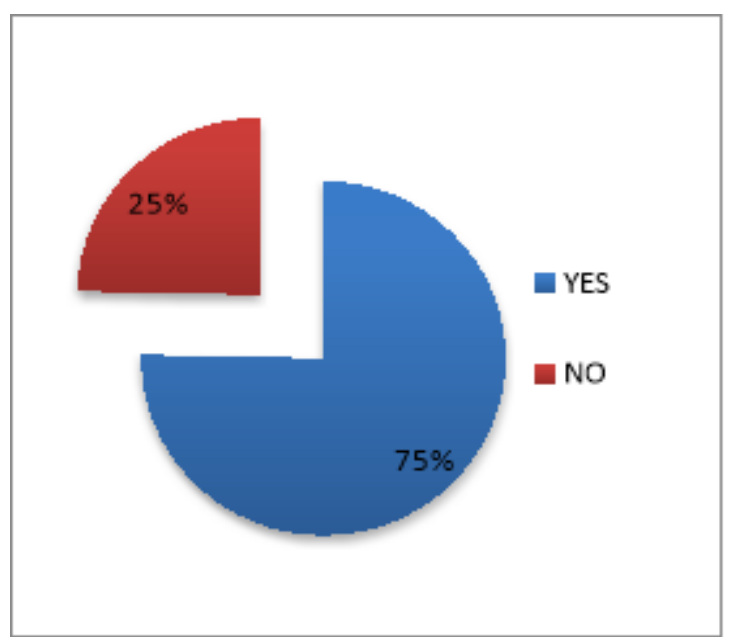

Fig. 4: have you ever done a digital rectal examination

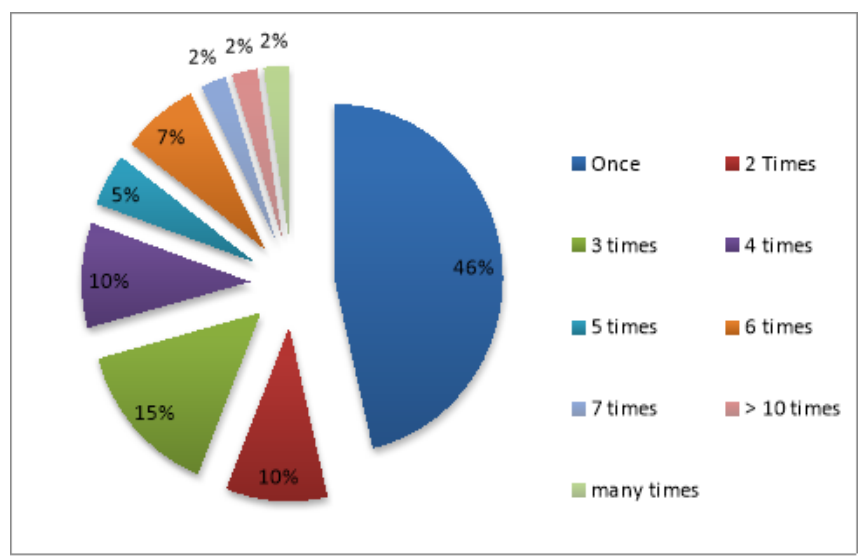

Fig 5. How many times dre performed

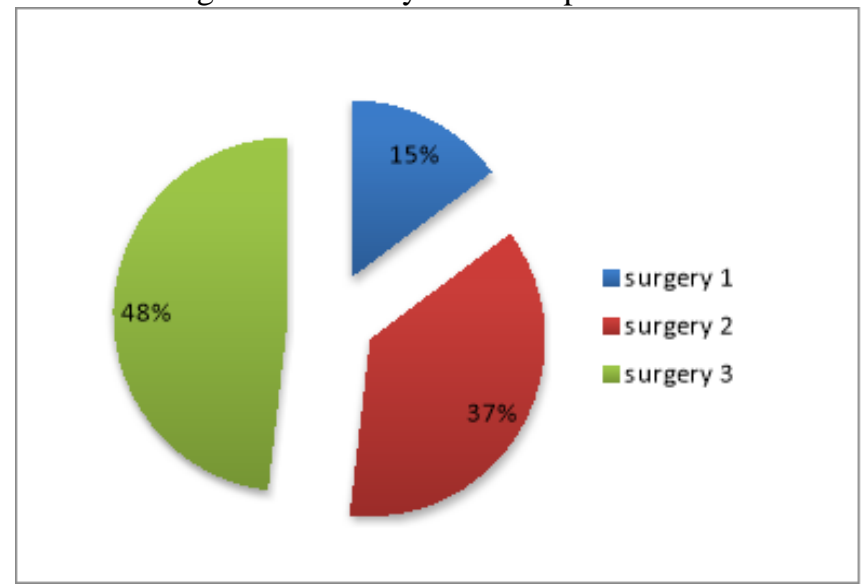

Fig 6: at which level of your training did you do dre?

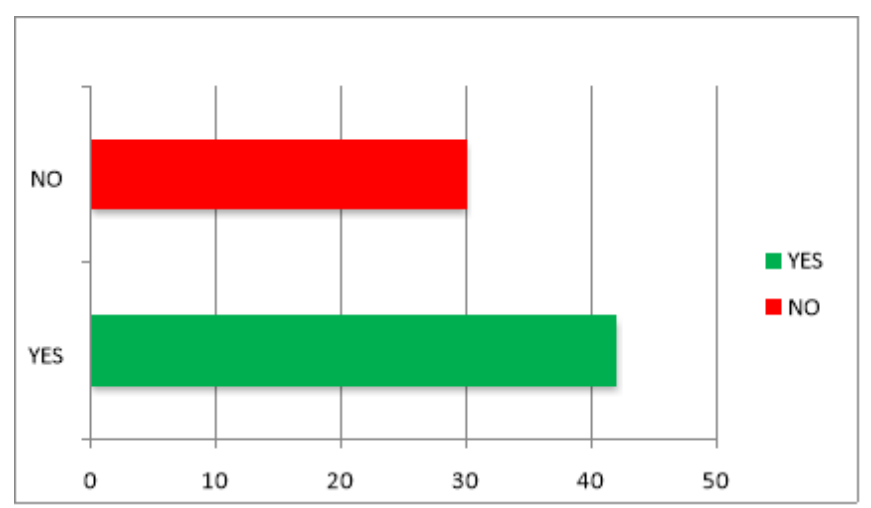

Fig. 7: if a colleague requires dre, will you perform it? 
World Journal of Innovative Research (WJIR)

ISSN: 2454-8236, Volume-6, Issue-5, May 2019 Pages 30-33

\section{DISCUSSION}

Digital rectal examination remains a relevant clinical tool in the diagnosis and prediction of prostate diseases [1]-[2] It is more handy in the developing nations where sophisticated medical tests and equipment remains luxury. The future custodians of our health, the present day medical students are expected to graduate with some basic skills irrespective of the specialty they wish to undertake in the future [11]. These skills could prove to be difference between diagnosing a case to a grievous omission that could lead to fatal outcomes. Based on this, I undertook to investigate the knowledge and the practice of digital rectal examination after they concluded all their postings and about to face their exit examination.

I found that out of the 120 respondents who consented to the study,70 were male and 50 were females showing a male to female ratio of $1.4: 1$

[Fig 1]which is different from the finding of Darkum $\mathrm{K}$ et al[12] who has a ratio of $3.6: 1$. 95\% accepted that they have been taught DRE which showed a high number of student who have received tutorial on DRE. This is consistent with the findings Eziyi et al [10] and Darkum et al[12]. [Fig 2]

About $75 \%$ of those who have been taught have done digital rectal examination, $25 \%$ have never attempted it.[Fig 4]. Of the $75 \%$ who have done digital rectal examination, only $14 \%$ of them have performed it up to 5 times and above [Fig 5]. The rest have done below 4 times. This is very low considering the number of patients who pass through our clinics and wards on daily basis with gastrointestinal problems and also in view the fact that gastrointestinal examinations are not complete until DRE is performed. This raises a lot of concern on the quality of physical examination being performed by our medical students and whether they are being well supervised during postings. Of those who were able to perform DRE, $15 \%$ of them did it during surgery 1 posting , 37\% performed DRE during surgery 2 posting while the $48 \%$ were only able to perform it in their last (surgery 3) posting. The rest could not remember.[Fig 5].

Most of the respondent (95\%|) have adequate knowledge of normal and abnormal findings on DRE,

Ten precent of the students did not perform DRE due to patient's refusal while $15 \%$ did not want to disturb the patient.

Nineteen percent of them do not believe DRE is for medical student, while $20 \%$ believe that their choice of future specialty affected their attitude toward DRE.

Fifty students representing $42 \%$ of all students who took part in the study think DRE is not necessary for patients with hemoptysis showing their limited knowledge of pathogenesis of rectal tumors.

$59 \%$ of all the students regretted not applying themselves fully to their postings.

\section{CONCLUSION}

Even though there is a demonstrable knowledge among these final year medical students on the normal and abnormal finding on digital rectal examination, it remains largely theoretical as greater number of them have not been able to perform this examination to a level one can be confident that they would not miss important findings which could be fatal.
It is therefore important that trainers give good attention to performance of physical examinations by their trainees to ensure that our young doctors do not become theoretical doctors.

\section{ACKNOWLEDGEMENT}

\author{
Prof Linus Okeke \\ Prof OB Shittu \\ Prof EO Olapade-Olaopa \\ Division of Urology \\ $\mathrm{UCH}$, Ibadan,Nigeria.
}

\section{REFERENCES}

[1] H. Ballentine Carter, MD; Jonathan I. Epstein, MD; Daniel W. Chan, $\mathrm{PhD}$; Recommended Prostate-Specific Antigen Testing Intervals for the Detection of Curable Prostate Cancer, JAMA 1997;277(18):1456-1460. doi:10.1001/jama.1997.03540420052029

[2] Fritz H. Schröder Arto Boeken Kruger John Rietbergen Ries Kranse Paul van der Maas Petra Beemsterboer Robert Hoedemaeker, Evaluation of the Digital Rectal Examination as a Screening Test for Prostate Cancer JNCI: Journal of the National Cancer Institute Volume 90, Issue 23, 2 December 1998, Pages 1817-1823, https://doi.org/10.1093/jnci/90.23.1817

[3] William J. Catalona, Jerome P. Richie, Frederick R. Ahmann, M'Liss A. Hudson, Peter T. Scardino , Robert C. Flanigan ,Jean B. Dekernion ,Timothy L. Ratliff, Louis R. Kavoussi ,Bruce L. Dalkin ,W. Bedford Waters ,Michael T. Macfarlane, and,Paula C. Southwick Comparison of Digital Rectal Examination and Serum Prostate Specific Antigen in the Early Detection of Prostate Cancer: Results of a Multicenter Clinical Trial of 6,630 Men Journal of Urology1 May 1994 https://doi.org/10.1016/S0022-5347(17)35233-3

[4] GUSTAVO F. CARVALHAL,DEBORAH S. SMITH,DOUGLAS E MAGER, CHRISTIAN RAMOS , and, WILLIAM J. CATALONA DIGITAL RECTAL EXAMINATION FOR DETECTING PROSTATE CANCER AT PROSTATE SPECIFIC ANTIGEN LEVELS OF 4 NG./ML. OR LESS , Journal of UrologyClinical Urology,1 Mar 19, https://doi.org/10.1016/S0022-5347(01)61785-3

[5] William J. Ellis ,Michael P. Chetner , Steven D. Preston, and,Michael K. Brawer, Diagnosis of Prostatic Carcinoma: The Yield of Serum Prostate Specific Antigen, Digital Rectal Examination and Transrectal Ultrasonography, Journal of urology, Volume

Issue 5 Part 1November 1994 Page: 1520-1525, https://doi.org/10.1016/S0022-5347(17)32460-6

[6] Fritz HSchröder , ${ }^{\mathrm{a}}$ MoniqueRoobol-Bouts ${ }^{\mathrm{a}}$ André NVis ${ }^{\mathrm{b}}$,Theovan der Kwast, ${ }^{b}$ RiesKranse ${ }^{a}$ Prostate-specific antigen-based early detection of prostate cancer-validation of screening without rectal examination Urology Volume 57, Issue 1, January 2001, Pages 83-90, https://doi.org/10.1016/S0090-4295(00)00863-3

[7] Arjen Hoogendam Frank Buntinx Henrica CW de Vet, The diagnostic value of digital rectal examination in primary care screening for prostate cancer: a meta-analysis, Family Practice, Volume 16, Issue 6, December 1999, Pages 621-626, https://doi.org/10.1093/fampra/16.6.621

[8] Onisuru T.Okotie Kimberly A.Roehl ${ }^{\mathrm{b}}$ MisopHan ${ }^{\mathrm{a}}$ StacyLoeb ${ }^{\mathrm{c}}$ Sara N.Gashti ${ }^{\mathrm{a}}$ William J.Catalona ${ }^{\mathrm{a}}$ Characteristics of Prostate Cancer Detected by Digital Rectal Examination Only, Urology Volume 70, Issue 6, December 2007, Pages 1117-1120.

[9] Jerome P. Richie, Louis R. Kavoussi George T. Ho, Martyn A. Vickers, Michael A. O'Donnell,Donna St. Laurent, Antony Chen,David S. Goldstein, Kevin R. Loughlin, Prostate cancer screening: Role of digital rectal examination and prostate-specific antigen, Annals of Surgical Oncology March 1994, Volume 1, Issue 2 , pp 117-120 
[10] A.K Eziyi, A.O Ademuyiwa, J.A.E Eziyi, A.A Salako Digital Rectal Examination for Prostate and Rectal Tumour: Knowledge and Experience of Final Year Medical Students, WAJM 2009; 28(5): 318-322.

[11] Titilola O Akinremi, Chidiebere N Ogo and ,Ayodeji O Olutunde, Review of prostate cancer research in Nigeria, Infectious Agents $\begin{array}{llll}\text { and } & \text { Cancer20116 } & \text { (Suppl } & \text { 2) }\end{array}$ https://doi.org/10.1186/1750-9378-6-S2-S8.

[12] Dakum K, Ramyil VM, Agbo S, Ogwuche E, Makama BS, Kidmas AT: Digital rectal examination for prostate cancer: attitude and experience of final year medical students. Niger J Clin Pract. 2007, 10 (1): 5-9. 